\title{
BAHASA RUPA PADA APLIKASI EDUKASI BATIK NUSANTARA
}

\author{
Farid Abdullah ${ }^{1}$, Bandi Sobandi ${ }^{2}$, Dewi M. Sya'bani ${ }^{3}$, Nurul Hidayah ${ }^{4}$ \\ Bambang Tri Wardoyo ${ }^{5}$, Akkapurlaura ${ }^{6}$ \\ 1,2,3 Departemen Pendidikan Seni Rupa, Fakultas Pendidikan Seni dan Desain, \\ Universitas Pendidikan Indonesia, Jl. Dr. Setiabudhi 229, Bandung - 40154 \\ 4Program Studi Pendidikan Guru Sekolah Dasar, Universitas Pendidikan Indonesia, \\ Jl. Cibiru Wetan no.15, Bandung - 40625 \\ 5,6Program Studi Desain Komunikasi Visual, Fakultas Seni Rupa dan Desain, Universitas Trisakti, \\ Jl. Kyai Tapa no.1, Jakarta Barat - 11440 \\ Email: bambangtri@trisakti.ac.id
}

\begin{abstract}
Abstrak Permasalahan selama dalam mempelajari batik adalah sesuatu yang rumit, kurang menyenangkan, serius, dan relatif sulit dipahami bagi usia awal. Mempelajari Batik Nusantara sesungguhnya dapat dilakukan melalui berbagai cara, namun terbaik disajikan edukatif, menyenangkan, bermain, dan mudah dipahami. Batik Nusantara merupakan salah satu media aplikasi edukasi yang sangat interaktif, memiliki tampilan rupa (user interface) mudah dipahami berbagai usia, mudah diunduh (download), dan tanpa berbayar. Metode tulisan ini adalah deskriptif-kualitatif, dengan mengunduh berbagai tampilan visual muka aplikasi edukasi Batik Nusantara kemudian dikaji memakai prinsip-prinsip Bahasa Rupa Primadi Tabrani. Hasil kajian aplikasi edukasi Batik Nusantara memakai Bahasa Rupa memperlihatkan kesesuaian visual Bahasa Rupa dengan pemahaman pengguna (user) untuk mengenal lebih dalam Batik Nusantara. Manfaat penelitian ini adalah aplikasi edukasi Batik Nusantara dan aplikasi-aplikasi digital lainnya dapat dikaji melalui prinsip-prinsip Bahasa Rupa yang membantu pemahaman pengguna menjadi lebih mudah.
\end{abstract}

Kata kunci: desain, Bahasa Rupa, aplikasi edukasi, Batik Nusantara

Abstract Problems in learning batik are complex, unpleasant, serious, and relatively difficult to understand at an early age. Learning Batik Nusantara can be done in several ways; however, it is best served as educational, fun, playful, and easy to understand. Batik Nusantara is one of the digital educational media that is very interactive, it has a user interface that is easy to understand for all ages, and it is easy to download, and free of charge. The method of this article is descriptive-qualitative, by downloading various visual displays of Batik Nusantara education application platform, then studying it using the principles of Bahasa Rupa, Primadi Tabrani. The results of the study of the Batik Nusantara educational application using Bahasa Rupa show the suitability of visual language with the user's understanding to get to know more in Batik Nusantara. The urgency of this research is the Batik Nusantara educational application and other digital applications can be studied through the Bahasa Rupa, Primadi Tabrani principles.

Keywords: design, Bahasa Rupa, education application, Batik Nusantara 


\section{PENDAHULUAN}

Berbagai usaha dilakukan untuk memperkenalkan dan mempelajari Batik Nusantara. Batik merupakan artefak budaya yang telah mendapat pengakuan Badan Pendidikan, Keilmuan dan Budaya Persatuan BangsaBangsa (UNESCO) pada 2 Oktober 2009 sebagai warisan tak benda bagi kemanusiaan (Intangible Heritage of Humanity). Keberadaan batik di Indonesia tersebar luas di berbagai kepulauan, mulai dari Sumatera, Jawa, Bali, Kalimantan, Sulawesi, hingga Papua yang kemudian disebut sebagai Batik Nusantara. Luasnya rentang keberadaan Batik Nusantara tersebut, maka diperlukan media yang interaktif untuk mempelajarinya, khususnya untuk generasi era 4.0. Mempelajari keberadaan batik maka akan terbentuk harmoni sosial bagi masyarakat global (Meliono, 2014).

Era Revolusi Industri 4.0 saat ini menawarkan luasnya kemungkinan, peluang, manfaat, namun di sisi lain adanya tantangan besar yang harus dihadapi umat manusia. Tantangan besar yang akan dihadapi peradaban ketika menghadapi era 4.0 adalah munculnya resistensi terhadap perubahan demografi dan aspek sosial, ketidakstabilan kondisi politik, keterbatasan sumber daya, risiko bencana (termasuk pandemi Covid-19), dan tuntutan penerapan teknologi ramah lingkungan (Drath dan Horch, 2014). Permasalahan lain era 4.0 adalah kesenjangan yang sangat lebar dari sisi teknologi di dunia industri dengan kondisi kesiapan masyarakat menerima perubahan (Qin, 2016).

Selama ini proses mempelajari batik sangat berpusat kepada guru. Siswa dalam mempelajari batik dituntut patuh kepada guru. Ketika siswa pemula mempelajari batik di luar arahan guru, maka dapat berpengaruh pada keluaran akhirnya. Di sisi lain, sumber daya manusia unggul adalah kunci utama kemajuan suatu bangsa. Sangat penting untuk ditekankan pada sumber daya manusia untuk produktif, kreatif, dan fokus kepada hasil (outcome), serta 
menjadikan inovasi sebagai budaya (Mandalika dan Syahril, 2020) yang tidak selalu berpusat pada guru. Selain itu, konotasi di masyarakat dalam mempelajari batik adalah sesuatu yang rumit, berat, memerlukan kajian literatur tertentu, dan terbatas bagi kalangan dewasa.

Dunia pendidikan saat ini hidup dalam dunia media. Di berbagai kegiatan belajar, telah mengarah menuju dikuranginya sistem bahan pengajaran dengan metode ceramah dan diganti dengan penggunaan media pembelajaran (Miftah, 2013). Format media pembelajaran pun sangat beraneka, termasuk media aplikasi edukasi. Dalam berbagai aktivitas, aplikasi edukasi tersebut juga memunculkan wacana negatif sebagai produk yang membuat kecanduan dan mendorong emosi negatif pada penggunanya (Bastian, 2016). Namun demikian, aplikasi edukasi sebagai suatu media belajar sangat mendukung dalam kondisi belajar dan bekerja di rumah (Work and Study from Home) saat ini.

Pengertian aplikasi edukasi adalah permainan yang dirancang atau dibuat untuk merangsang daya pikir, termasuk meningkatkan konsentrasi dan memecahkan suatu masalah. Aplikasi edukasi merupakan satu media yang digunakan untuk memberikan pengajaran, menambah pengetahuan pengguna melalui media digital dan menarik (Delima, 2016). Aplikasi edukasi merupakan salah satu media pembelajaran yang banyak diciptakan (Rahmasari dan Yanuarsari, 2017) saat ini. Agar efektif, suatu aplikasi edukasi berbasis sistem Android memiliki sejumlah kriteria. Terdapat 7 (tujuh) syarat agar satu aplikasi edukasi memenuhi kriteria memadai, antara lain: (1) Nilai Keseluruhan; (2) Dapat dipakai; (3) Ketepatan; (4) Kepantasan; (5) Kesesuaian; (6) Objektif; dan (7) Memiliki Umpan Balik (Hurd dan Jenuings, 2009). Maka, pertanyaan artikel ini adalah bagaimana Bahasa Rupa yang tepat untuk suatu aplikasi edukasi yang efektif dan menyenangkan untuk generasi era 4.0. 
Aplikasi edukasi seperti Batik Nusantara dapat dikaji memakai berbagai pendekatan. Kebaruan (novelty) dari tulisan ini adalah aplikasi edukasi Batik Nusantara belum pernah sebelumnya dikaji melalui prinsip Bahasa Rupa, Primadi Tabrani. Pemakaian prinsip Bahasa Rupa RWD (Ruang Waktu Datar), Primadi Tabrani, telah dipakai untuk bidang desain grafis (Haryadi dan Saputro, 2019) dan memudahkan pengkajian suatu objek visual.

\section{METODE PENELITIAN}

Penelitian ini memakai pendekatan deskriptif-kualitatif. Untuk mengetahui lebih jauh pengertian dari deskriptif dalam suatu penelitian adalah "Karya tulis prosa yang subyek karangannya memiliki aspek tampilan (visual). Suatu karya ilmiah yang mencatat atau merekam suatu subyek" (Tjuparmah dan Yooke, 2007: 55). Metode penelitian deskriptif bertujuan menguraikan kondisi yang ada untuk kemudian memaparkan melalui suatu deskripsi. Metode deskriptif dapat diterapkan dalam berbagai penelitian Bahasa Rupa, seni, dan desain dengan syarat bahwa topik penelitian tersebut menyangkut observasi pada suatu objek yang diteliti (Sumartono, 2018: 13). Sedangkan kualitatif adalah prosedur penelitian yang dilakukan dengan pengumpulan data deskriptif seperti ucapan, tulisan, dan perilaku dari orangorang atau subyek yang diamati. Penelitian kualitatif memungkinkan untuk memperoleh pemahaman tentang suatu kenyataan melalui proses berpikir induktif (Bogdan dan Taylor, 1992: 21).

Untuk membedah aplikasi edukasi Batik Nusantara, dipakai prinsipprinsip Bahasa Rupa Primadi Tabrani. Pemilihan Bahasa Rupa Tabrani mempertimbangkan 'kelokalan' dari prinsip-prinsipnya, hasil dari penelitian disertasi Tabrani yang dilakukan pada relief Lalitavistara, candi Borobudur pada tahun 1991. Prinsip-prinsip Bahasa Rupa Tabrani juga merupakan hasil 
studi perbandingan berbagai Bahasa Rupa seperti gambar anak-anak, gambar gua prasejarah, gambar primitif, gambar Wayang Beber Jaka Kembang Kuning, dan karya seni rupa modern Indonesia (Tabrani, 2018).

Prinsip-prinsip untuk mempergunakan Bahasa Rupa Primadi Tabrani secara dasar dijelaskan sebagai berikut: (1) cara digeser; (2) cara dari kepalakaki, atas-bawah; (3) cara tampak khas; (4) cara media dingin; (5) tanpa bingkai, tanpa perspektif, tanpa perbesar (zoom in) dan perkecil (zoom out); (6) cara diperbesar dan cara diperkecil; (7) tanpa perspektif (Tabrani, 2018: 188). Prinsip-prinsip tersebut kemudian dipergunakan untuk menelaah tampilan aplikasi edukasi Batik Nusantara.

\section{HASIL DAN DISKUSI}

Profil

Aplikasi edukasi tentang batik terhitung ada beberapa di Google Playstore berbasis Android. Adapun karya anak bangsa aplikasi edukasi terkait batik cukup banyak, antara lain: Filosofi Batik, Mbatik (Mari Belajar Batik), Desain Batik, termasuk Batik Nusantara. Pertimbangan pemilihan aplikasi Batik Nusantara dalam penelitian ini adalah tampilan muka (user interface) yang menarik dan usia pembuatan aplikasi ini yang relatif baru yaitu tahun 2018. 


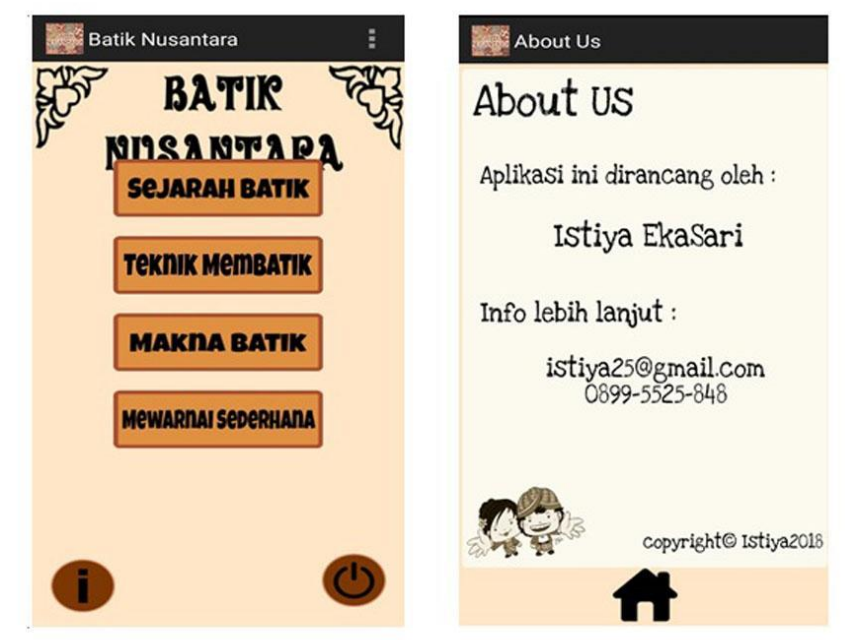

Gambar 1. Tampilan awal dan profil aplikasi edukasi Batik Nusantara [sumber: screenshoot Batik Nusantara, 2020]

Aplikasi edukasi Batik Nusantara (Gambar 1) dibuat oleh Istiya Ekasari, sebagai bagian dari tugas akhir, pada tingkat strata S1, Fakultas Komputer, Universitas MH. Thamrin, Jakarta dan dirilis pada 22 Juli 2018. Aplikasi edukasi Batik Nusantara versi 1.0 memiliki ukuran file terhitung kecil yaitu 37,91 MB dan data berukuran 32,77 kB, maka total yang dibutuhkan untuk menjalankan aplikasi edukasi Batik Nusantara adalah 38,03 MB. Hingga bulan Oktober 2020, aplikasi ini memiliki rating 3+, yang menjelaskan bahwa penilaian pengguna (user) terhadap aplikasi ini cukup baik.

Konten aplikasi edukasi Batik Nusantara terdiri atas 4 segmen, yaitu: (a) Sejarah Batik; (b) Teknik Membatik; (c) Makna Batik; dan (d) Mewarnai Sederhana. Keberadaan 4 segmen tersebut menjelaskan kepada pengguna (user) tentang wawasan sejarah, teknik produksi batik, wawasan makna motif-motif batik, serta interaktif dalam proses pewarnaan motif batik pada busana. Pada bagian terakhir yaitu (d) Mewarnai Sederhana, merupakan bagian yang mengajak pengguna untuk interaktif mencoba, mengatur, dan menata warna-warna pada produk busana yang sudah tersedia. 
Pada sebuah aplikasi edukasi diperlukan konsep yang kuat dan menarik. Untuk itu, pada sebuah aplikasi edukasi Batik Nusantara juga harus memperhatikan aspek visual, yang diwujudkan dalam desain rupa sebagai media interaksi dengan pengguna (Khamadi, 2015). Aspek rupa memegang peranan penting untuk menarik minat juga bertujuan memperlihatkan pesan pertama bagi pemain.

\section{Analisa Bahasa Rupa Batik Nusantara}

Tampilan awal rupa aplikasi edukasi memegang peranan penting yang dapat menarik pengguna untuk memainkannya. Tampilan awal adalah wajah representasi tubuh aplikasi edukasi. Pada tampilan awal (Gambar 1.) aplikasi edukasi Batik Nusantara, memakai prinsip Bahasa Rupa maka cara membaca menurut Bahasa Rupa adalah atas ke bawah, atau dari kepala ke kaki. Bahasa Rupa atas ke bawah ini sangat mudah dipahami, mengingat layar suatu gawai (gadget) umumnya dipergunakan vertikal.

Pemilihan warna dominan aplikasi edukasi Batik Nusantara adalah warna sogan (coklat muda, coklat tua, dan hitam). Pemakaian warna sogan ini dalam Bahasa Rupa dapat dimasukan sebagai prinsip Media Dingin, yaitu pengguna aplikasi dapat aktif berimajinasi, berpikir, dan menangkap keadaan sebenarnya (Tabrani, 2018: 188). Demikian juga pada keseluruhan tampilan segmen Batik Nusantara, memiliki prinsip Bahasa Rupa Tampak Khas, yaitu semua objek dapat dilihat, dibaca, dan mudah dipahami oleh pengguna (Tabrani, 2018: 187). 


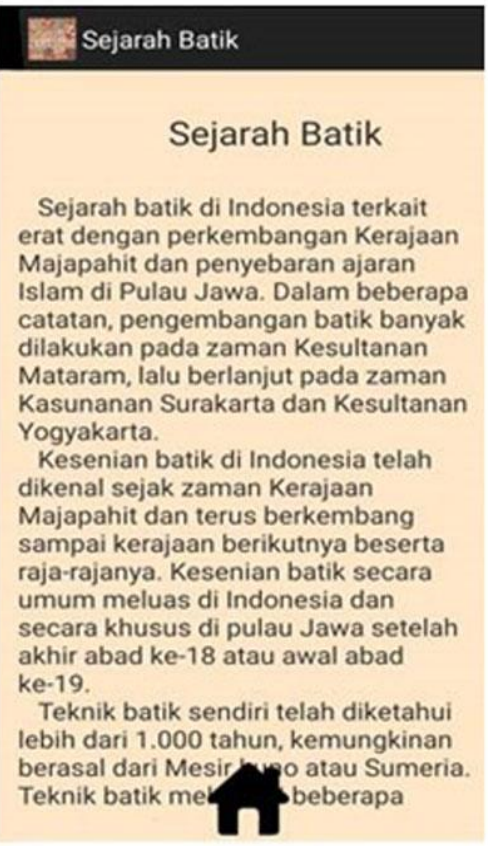

[a]

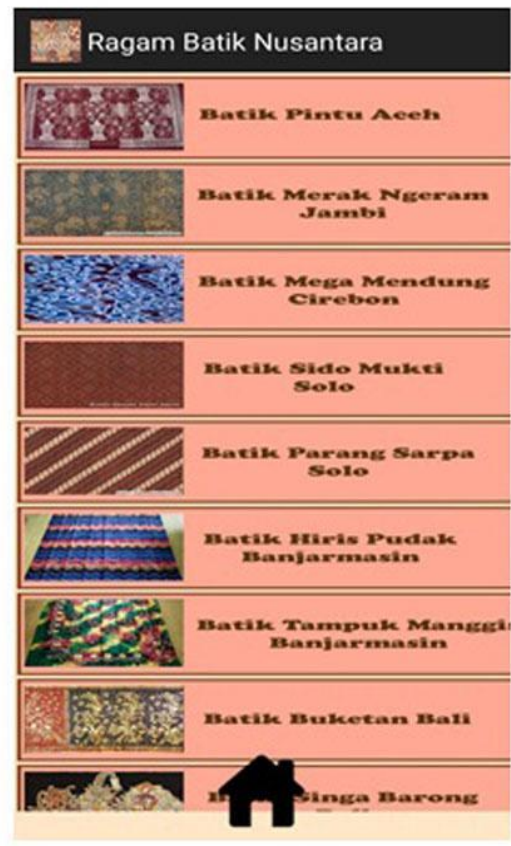

[b]

Gambar 2. Tampilan Sejarah dan Ragam Batik Nusantara

[Sumber: screenshoot Batik Nusantara, 2020]

Tampilan segmen kedua adalah Sejarah Batik dan Ragam Batik Nusantara (Gambar 2). Pada segmen ini, Bahasa Rupa untuk membaca aplikasi edukasi Batik Nusantara adalah dari atas ke bawah, berupa teks tentang sejarah batik di Indonesia. Pada segmen ini, ditemui kekurangan visual untuk mendukung sejarah batik agar lebih menarik. Visualisasi menjadi penting untuk memperkuat narasi deskriptif tentang sejarah batik. Visual yang ditemukan pada segmen ini hanya ikon rumah (home) yang menjelaskan arah kembali ke segmen awal bagi pengguna aplikasi ini.

Pada tampilan Ragam Batik Nusantara [b], memperlihatkan beberapa kain batik dalam perspektif. Adanya perspektif tersebut menjelaskan juga tentang ukuran kain batik yang banyak dibuat dalam ukuran helai memanjang. Penggambaran perspektif ini memudahkan pemahaman bagi 
pembelajar batik pemula seperti anak-anak atau orang yang awam terhadap batik.

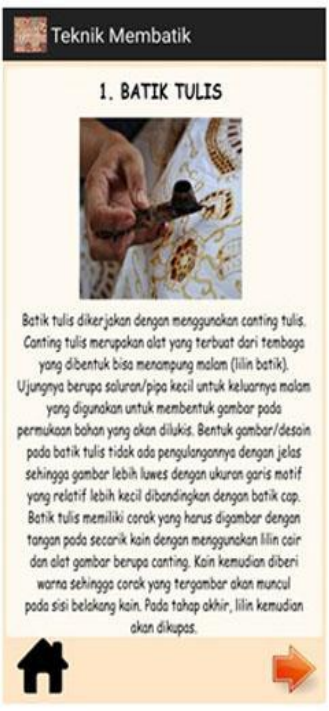

[a]

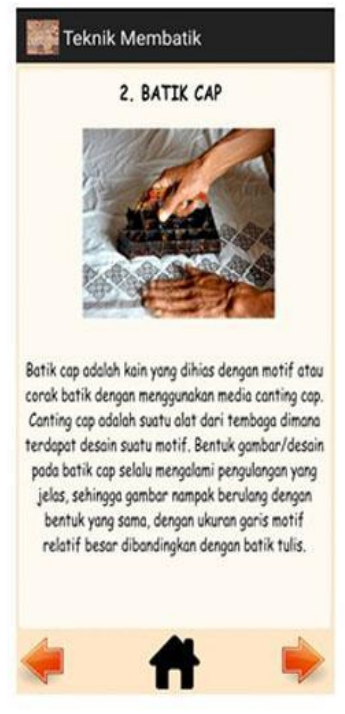

[b]

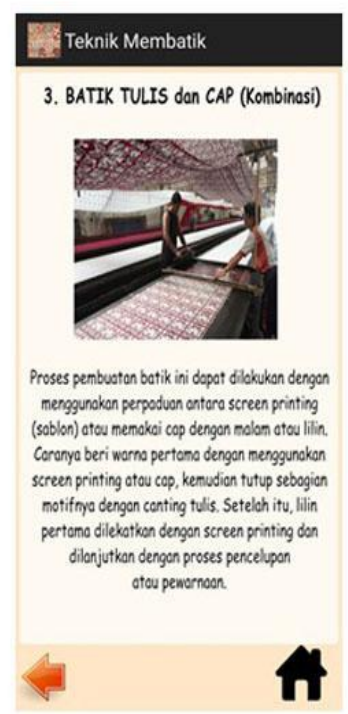

[c]

Gambar 3. Tampilan Teknik Membatik aplikasi edukasi Batik Nusantara

[Sumber: screenshoot Batik Nusantara, 2020]

Pada segmen ketiga adalah Teknik Membatik (Gambar 3). Segmen ini memperlihatkan 3 teknik batik yaitu: (1) Batik Tulis; (2) Batik Cap; dan (3) Batik Tulis dan Cap (kombinasi). Visualisasi pada segmen ini sudah dilengkapi dengan foto yang sangat membantu pemahaman pengguna.

Bahasa Rupa pada segmen ketiga ini memiliki struktur tampilan serupa, yaitu judul Batik Nusantara di bagian atas, teks narasi tentang teknik batik di tengah, foto yang menjelaskan teknik batik dan narasi penjelas dari foto. Pada bagian bawah terdapat visual ikon rumah di bagian kiri dan tanda penunjuk halaman berikut pada bagian kanan.

Memakai prinsip Bahasa Rupa, keseluruhan tampilan memakai metode Tampak Khas, yaitu semua objek bisa dilihat, dibaca, diceritakan dan sulit disalah tafsirkan (Gambar 3. [a], [b], [c]). Namun demikian, untuk foto penjelas pada bagian tengah, terdapat prinsip diperbesar (zoom in) dan 
diperkecil (zoom out) dan memiliki perspektif. Diperbesar dapat terlihat pada foto tangan memegang canting [a] dan cap batik [b], sedangkan perspektif terlihat pada foto teknik batik tulis dan cap [c].

Pada bagian bawah segmen ketiga, terdapat ikon rumah (home) dan tanda penunjuk ke halaman berikut. Prinsip Bahasa Rupa pada bagian ini adalah membaca kanan-kiri atau sebaliknya.

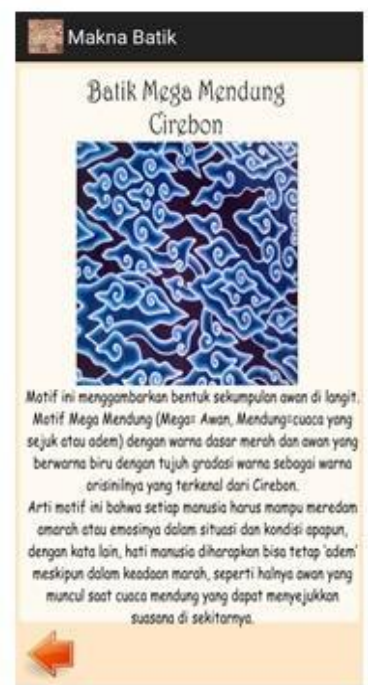

[a]

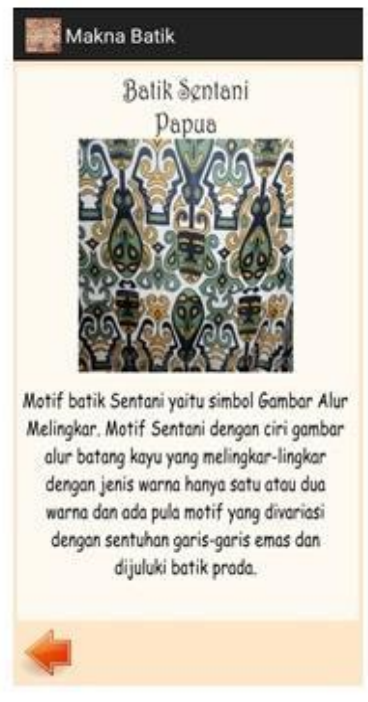

[b]

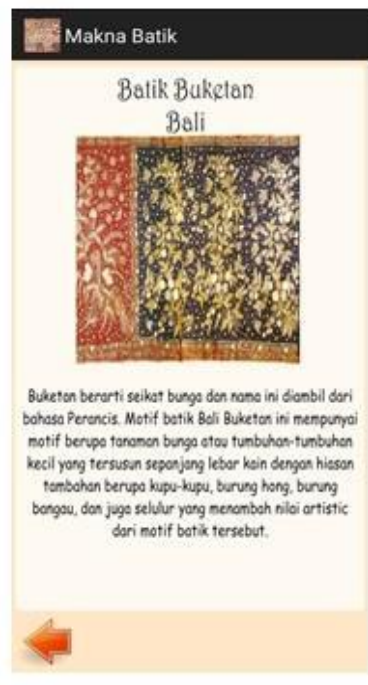

[c]

Gambar 4. Tampilan Makna Batik Nusantara

[Sumber: screenshoot Batik Nusantara, 2020]

Pada segmen keempat adalah Makna Batik (Gambar 4) di atas ini. Bahasa Rupa pada segmen keempat pada aplikasi edukasi Batik Nusantara memiliki struktur visual yang sama, yaitu teks Makna Batik di bagian atas, judul dan foto pola batik di bagian tengah, teks narasi penjelas di tengah bawah, dan tanda panah di bagian bawah.

Prinsip Bahasa Rupa untuk membaca (Gambar 4), secara keseluruhan tampilan memakai prinsip Tampak Khas, yaitu semua objek bisa dilihat, dibaca, diceritakan dan mudah dipahami (Gambar 4. [a], [b], [c]). Tampak struktur khas yang bertujuan memudahkan pengguna untuk memahami isi 
aplikasi edukasi Batik Nusantara. Demikian pula prinsip Bahasa Rupa yang dipakai untuk foto pola batik adalah Media Dingin dan tidak memiliki perspektif (Marshall McLuhan dalam Tabrani, 2018: 187). Pada foto yang memperlihatkan pola-pola batik daerah pada aplikasi edukasi Batik Nusantara tidak memperlihatkan perspektif.

Pada bagian bawah segmen keempat, terdapat ikon tanda penunjuk ke halaman kembali. Prinsip Bahasa Rupa pada bagian ini adalah membaca bagian kanan saja. Pengguna dapat mempergunakan ikon tanda panah ini relatif mudah dipahami untuk menjelaskan kembali ke halaman sebelumnya. Ikon tanda penunjuk ke arah kanan sangat memudahkan pengguna pemula untuk efektifitas tanda dan tidak membingungkan.

Segmen kelima dari aplikasi edukasi Batik Nusantara adalah Mewarnai (Gambar 5). Pada segmen ini, bersifat interaktif karena pengguna dapat mewarnai sejumlah busana yang telah tersedia termasuk pilihan pola dan warna batiknya. Aktivitas mewarnai melalui gawai (gadget) dirancang secara sederhana yaitu pengguna memilih warna-warna yang telah disediakan pada aplikasi Batik Nusantara. Produk yang dapat diwarnai juga telah disediakan, mulai kepala (topi, jilbab), perlengkapan pendukung (tas), badan (baju pria dan wanita), kaki (rok, celana panjang). Ketersediaan ini sangat membantu pengguna untuk membuat kreasi sendiri. 


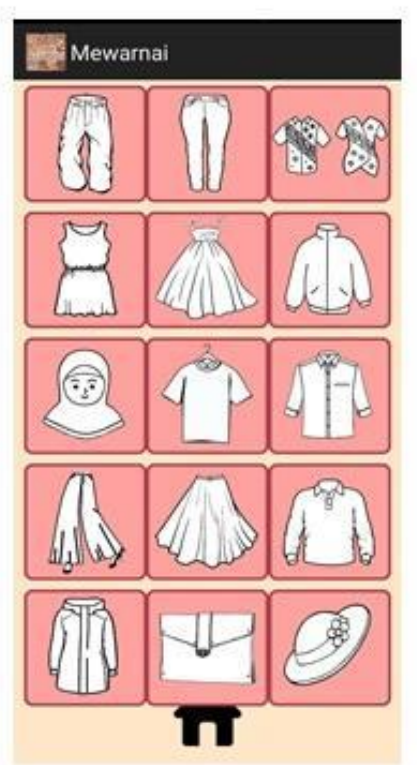

[a]

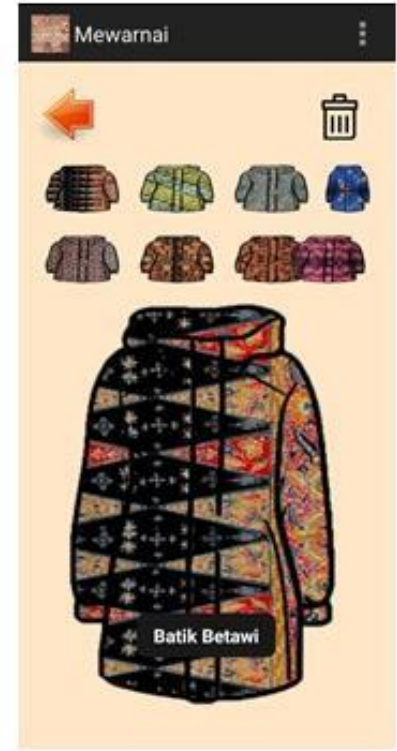

[b]

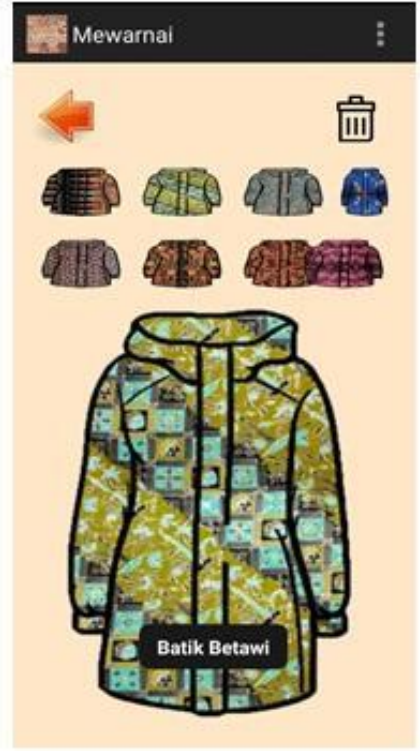

[c]

Gambar 5. Tampilan segmen mewarnai Batik Nusantara [Sumber: screenshoot Batik Nusantara, 2020]

Struktur pada segmen kelima ini dapat dikatakan berbeda dengan segmen-segmen sebelumnya. Struktur tampilan pada bagian awal Mewarnai [a] memperlihatkan aneka busana yang dapat dipilih oleh pengguna. Bahasa Rupa pada tampilan ini adalah memakai prinsip tampak khas, yaitu semua objek bisa dilihat, dibaca, diceritakan dan mudah dipahami (Gambar 5 [a]).

Pada bagian Mewarnai (Gambar 5 [b], [c]) struktur visual memiliki kesamaan yaitu bagian atas sebagai penjelas judul, di bagian tengah atas berupa tanda panah dan ikon tempat sampah sebagai petunjuk membatalkan atau membuang. Pada bagian tengah terdapat sejumlah pilihan visual mewarnai pola batik. Bahasa Rupa pada bagian ini memakai prinsip tanpa bingkai, tanpa perspektif, tanpa diperbesar (zoom in) dan diperkecil (zoom out).

Bahasa Rupa pada bagian segmen kelima (Gambar 5 [b], [c]) ini mempergunakan prinsip Media Dingin yaitu pengguna aktif berimajinasi, 
berpikir, dan mampu menangkap seakan realitas sebenarnya (Mc Luhan dalam Tabrani, 2018: 188). Pengguna (user) dapat berimajinasi seakan rancangannya memiliki warna dan komposisi yang sesuai dengan pengalaman estetika yang dimilikinya. Segmen ini dapat disebut interaktif, karena pengguna dapat memasukan pilihannya serta mengapresiasi hasil karyanya kepada sesama pengguna lainnya.
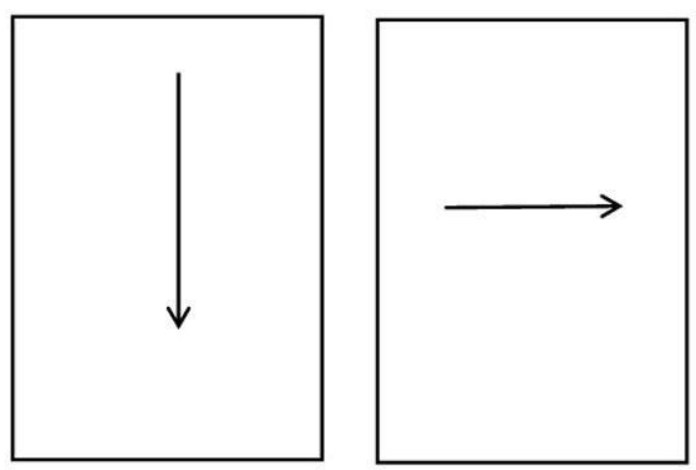

[a]

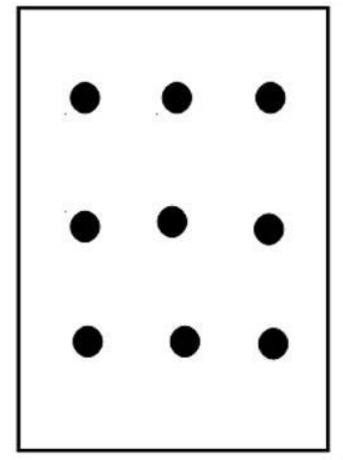

[b]

[c]

Gambar 6. Prinsip Bahasa Rupa dominan pada Batik Nusantara

Dari seluruh tampilan aplikasi edukasi Batik Nusantara di atas, maka dapat diperoleh prinsip-prinsip Bahasa Rupa yang dominan dipakai pada aplikasi tersebut. Berikut pada Gambar 6 diperoleh struktur Bahasa Rupa yang banyak dipergunakan.

Pada Gambar 6 [a] di atas adalah Bahasa Rupa dari kepala - kaki, atau dari atas - bawah. Pemakaian ini relatif mudah dipahami dan menjadi kelaziman pengguna (user) saat memegang gawai (gadget). Cara membaca Bahasa Rupa ini banyak ditemui pada media-media lainnya, baik surat kabar atau media cetak yang banyak dipakai oleh pengguna pemula.

Pada Gambar 6 [b] adalah Bahasa Rupa bergeser, dari kanan - kiri. Pemakaian kanan - kiri ini lazim dipergunakan untuk membaca teks atau 
narasi yang menjelaskan suatu objek. Pemakaian Bahasa Rupa ini sifatnya sekunder, setelah pengguna melihat objek visual. Terdapat kecenderungan pengguna pemula akan melihat aspek rupa, kemudian disusul membaca narasi atau teks penjelas.

Selanjutnya Gambar 6 [c] adalah prinsip Media Dingin yaitu pengguna (user) aktif berimajinasi, berpikir, agar mampu 'menangkap' kejadian sebenarnya (Marshall McLuhan dalam Tabrani, 2018: 187). Prinsip Media Dingin ini ditawarkan pada segmen mewarnai dari aplikasi edukasi Batik Nusantara. Pada prinsip Media Dingin, adalah proses interaktif antara pengguna dalam memilih warna dan pola batik. Pada tahap ini, terdapat proses kreasi dan imajinasi yang mendorong pengguna untuk berimajinasi, berpikir dan berlatih mengkomposisi suatu produk batik.

Prinsip Bahasa Rupa diperbesar (zoom in) dan diperkecil (zoom out) dan perspektif, tampaknya tidak menjadi dominan di aplikasi edukasi Batik Nusantara. Keberadaan perspektif hanya ditemui pada ilustrasi foto-foto yang menjelaskan teknik produksi batik.

\section{KESIMPULAN}

Kemampuan adaptif suatu produk budaya adalah tuntutan mutlak di era 4.0. Sebagai satu produk budaya adiluhung, Batik Nusantara, juga sepantasnya bertransformasi adaptif menawarkan format-format baru, seperti aplikasi edukasi Batik Nusantara. Kemampuan adaptif mengikuti semangat zaman, loT (Internet of Things) merupakan keniscayaan, apabila artefak batik agar terus hidup di masyarakat. Kemampuan adaptif ini tentu dilakukan dengan menyesuaikan alam pikiran pengguna (user) era 4.0. Maka keberadaan aplikasi edukasi seperti Batik Nusantara, dan aplikasi-aplikasi lainnya yang mengangkat produk budaya, sangat perlu didukung oleh seluruh pemangku kepentingan (stakeholders). 
Batik telah diakui badan dunia UNESCO sebagai warisan tak benda. Sebagai karya budaya yang mencapai puncak pencapaian tertinggi di Indonesia, adalah kebanggaan ketika aplikasi edukasi Batik Nusantara juga dihasilkan oleh anak bangsa Indonesia. Demikian pula pemilihan Bahasa Rupa sebagai prinsip-prinsip membaca rupa dilahirkan oleh Primadi Tabrani. Keseluruhan karya, penciptaan aplikasi edukasi dan pemakaian prinsip Indonesia ini sebagai pernyataan pengakuan seni (statement of the art) dari tulisan ini.

Terdapat keterbatasan (limitation) prinsip Bahasa Rupa untuk mengkaji objek aplikasi-aplikasi lain yang tidak cukup lengkap unsur-unsur rupa, contohnya pada aplikasi yang bertumpu pada audio atau suara. Saran untuk penelitian lanjutan khususnya aplikasi edukasi Batik Nusantara terletak pada beberapa bagian tampilan, yaitu perlu dilakukan perbaikan visualisasi, maka hal ini dapat dilakukan pada edisi update dari aplikasi edukasi Batik Nusantara (edisi 2.0, 3.0, dan seterusnya). Penilaian (review) dari peneliti perguruan tinggi desain sangat diperlukan untuk menelaah aplikasi-aplikasi lainnya, khususnya aplikasi edukasi agar memiliki kajian yang objektif.

\section{DAFTAR PUSTAKA}

Bastian, H. dan Khamadi. 2016. Dampak Digital Game Terhadap Perkembangan Sosial Budaya Masyarakat, Jurnal Andharupa, vol. 2(01), 33-44.

Bogdan, R.C. dan Taylors, K.B. 1992. Qualitative Research: An Introduction to Theory and Methods. Boston: Ally and Bacon Inc.

Drath, R., dan Horch, A. 2014. Industrie 4.0: Hit or Hype? [industry forum]. IEEE Industrial Electronics Magazine, 8(2), 56-58.

Delima, R., Arianti, N.K. dan Pramudyawardani, B. 2016. Pengembangan Aplikasi Permainan Edukasi untuk Anak Prasekolah Menggunakan Pendekatan Child Centered Design, Jurnal INFORMATIKA, vol. 12(1), 13-24. 
Haryadi, T. dan Saputro, G.E. 2019. Eksplorasi Bahasa Rupa RWD dalam Komunikasi Grafis (Studi Kasus: Karya Mahasiswa Tugas Akhir DKV). Demandia, 4(2): 157-171.

Hurd, D. dan Jenuings, E. 2009. Standardized Educational Games Ratings: Suggested Criteria, diunduh dari https://www.slideshare. net/Serinity/ educational-games-rating-system-suggested-criteria, pada 14 Juni 2020.

Khamadi. 2015. Analisis Tampilan Visual Game Super Mario Bros dalam Kajian Persepsi Visual sebagai Dasar Pengembangan Konsep Visual Game, Jurnal Andharupa, 1(02), 98-102.

Mandalika, M. dan Syahril, S. 2020. Pengembangan Media Pembelajaran Berbasis Video Tutorial untuk Meningkatkan Efektifitas Pembelajaran Pada Mata Kuliah Tata Rias, Jurnal Inovasi Vokasional dan Teknologi, 20(1), 85-92.

Meliono, I. 2014. Batik dan Industri Kreatif: Sebuah Proses Kreatifitas Manusia dalam Kajian Studi Humaniora, Paradigma: Jurnal Kajian Budaya, FIB UI, 4(2), 117-135.

Miftah, M. 2013. Fungsi dan Peran Media Pembelajaran sebagai Upaya Peningkatan Kemampuan Belajar Siswa, Jurnal KWANGSAN, vol. 1(2), 95115.

Qin, J., Liu, Y. dan Grosvenor, R. 2016. A Categorical Framework of Manufacturing for industry 4.0 and Beyond. Procedia CIRP, Vol. 52, 173-178.

Rahmasari, E.A. dan Yanuarsari, D.H. 2017. Kajian Usability dalam Konsep Dasar User Experience pada Game "ABC Kids-Tracing and Phonics" sebagai Media Edukasi Universal untuk Anak. Demandia, 2(1): 49-71.

Rakhmawati, Y. 2016. Batik Madura: Heritage Cyberbranding, Jurnal Komunikasi, vol.9(2), 57-65.

Sumartono. 2017. Metodologi Penelitian Kualitatif Seni Rupa dan Desain. Pusat Studi Reka Rancang Visual dan Lingkungan, Fakultas Seni Rupa dan Desain, Universitas Trisakti, Jakarta.

Tabrani, P. 2018. Prinsip-Prinsip Bahasa Rupa, Jurnal Budaya Nusantara, vol. 1(2), 173-195. 
Farid Abdullah, Bandi Sobandi, Dewi M. Sya'bani BAHASA RUPA PADA APLIKASI EDUKASI BATIK NUSANTARA, 66 - 82

Tjuparmah, K. dan Yooke. 2007. Kamus Istilah Karya Tulis Ilmiah, penerbit Bumi Aksara, Jakarta. 